\title{
SOLUBILITY OF BUTYL ACETATE IN UNSATURED AQUEOUS MIXTURES OF GLUCOSE, SUCROSE AND FRUCTOSE AT LOW TEMPERATURES.
}

\author{
F. C. Silva ${ }^{1}$, M. R. Franco $\mathrm{Jr}^{2}$ \\ ${ }^{1}$ IFTM - Instituto Federal do Triângulo Mineiro - Av. Rua Belarmino Vilela Junqueira s.n ${ }^{\circ}$, Bairro Novo \\ Tempo 2, CEP:38.305-200, Ituiutaba-MG - MG, Brasil \\ ${ }^{2}$ Faculdade de Engenharia Química, Universidade Federal de Uberlândia, Av. João Naves de Ávila 2121, \\ 38408-100, Uberlândia-MG, Brasil \\ Email para contato: moilton@ufu.br
}

Interactions between water and flavour molecules have been widely studied and are characterized by the hydrophobicity and volatility. The influence of different types of sugar should be known in case of they are part from the material. Flavour release from complex food matrices is difficult to predict and solubility data would be helpful. Thus, interactions between flavour molecules and other compounds are often investigated in binary and ternary model systems (e.g., water, flavour compounds, carbohydrates) to characterize specific release mechanisms.

In this paper, the solubility of butyl acetate from pure water and various lowviscosity aqueous solutions (D-Sucrose, D-Glucose, D-Fructose), at 10-30 $\mathrm{gL}^{-1}$, was investigated. Static isothermal method was used and concentrations of the aroma or flavour compound at thermodynamic equilibrium were monitored by analyzing liquid samples using gaseous chromatography. Experiments were carried out at temperature range of 278.25 - $298.2 \mathrm{~K}$. Flavour solubility from mixtures decreased with increasing temperature and decreased with molecular superficial area of the sugar compound. The flavour compound was retained more extensively in the presence of glucose agent, compared to in pure water, while an increase in the solubility was observed in presence of sucrose and fructose. All aqueous solutions had similar behavior as sugar concentration was increased, although it was expected that sugar molecular weight tended to have influences in the equilibrium concentration. A correlation between temperature (or sugar concentration) and butyl acetate solubility in the low-viscosity solutions was evident.

\section{INTRODUCTION}

Esters, alcohols and ketones are considered important with respect to fruit and synthetic drinks flavours. Furanones and esters have been described as the most important aroma-active constituents in sweets and juices (Blanch and Castillo, 2012). Among esters, ethyl and butyl acetate are included. The largest group of flavour compounds in wines consists of esters of the aliphatic monocarboxylic acids. Butyl acetate and many of the long-chain esters in wine are formed by yeast principally by enzymic reactions du ring fermentation and not in chemical reactions between ethanol and corresponding acids (Franco and Janzantti, 2005; Nykänen \& Suomalainen, 1983). It is known that $29 \%$ of compounds detected in nature fruit are esters. 
Also, they had a higher number of identified compounds, and the sweet fruity notes of acerola or cupuaçu aroma, for example, were attributed by their presence. Aliphatic esters comprised the largest class (31\%) of the total volatiles compounds found in the sweet fruity juice. The extract obtained from different fruit samples from Brazil presents a pleasant fruity sweet aroma, having higher proportions of sweet high-boiling compounds. (Franco and Janzantti, 2005).

The commercial interest in volatiles, such as butyl acetate, stems from their aromatic and flavour qualities. Several of them, have significant antimicrobial and antineoplastic activity. Volatiles are obtained from plants by distillation at or by extraction with organic solvents (ethanol, chloroform, hexane, benzene and so on). (Gounaris, 2010)

The exact compositions of many alcoholic beverages are trade secrets; however, there is extensive literature on the aroma components which are usually present at low levels, more than 1300 of which have been identified (Nykänen \& Suomalainen, 1983). Information about nonaroma compounds is less extensive. An interesting example is Chinese liquor (Fan and Qian, 2006) which has strong fruit, pineapple and banana-like aromas. Sixty-eight volatile components, including alcohols, esters, acids, acetals, ketones, aldehydes and heterocyclic compounds, have been identified in Chinese liquors (Fan and Qian, 2006). Very few studies report on aroma compounds in them. It would be very important the knowing of equilibrium concentration data to the aroma of Chinese aroma-type liquor, based on the calculated odour activity value. Up to now, no studies have reported on the contribution of aroma compounds to the characteristic bouquet of this liquor (Fan and Qian, 2006).

Juices were already characterized by sugar, amino acid, carboxylic acid and ash pseudocomponents in aqueous solution (Abderafi and Bounahmidi, 1999). To correlate interaction parameters of traditional or new equations, it is important to obtain experimental data for the systems involved. To study the distillation as well as extraction processes, will be necessary to obtain thermodynamic equilibrium data for the liquid-liquid equilibrium (Oliveira et al., 2007-2008; Malagoni and Franco, 2007; Pires and Franco, 2008; Oliveira, 2009) so as to determine the compositions and their possible industrial uses.

A viable candidate for use as an aroma is butyl acetate. However, it has not been possible to find in the literature (Borges et al., 2013) a comprehensive experimental study of its isobaric solubility in unsaturated mixtures of the water-glucose, water-fructose and water-sucrose systems at atmospheric pressure. Usually, the equilibrium data for this system, which are necessary for the design and simulation of the extraction and distillation process, have been obtained from predictions by means of thermodynamic models with parameters based on the correlation of binary VLE and LLE data.

In this work, solubility of butyl acetate in both pure water and several unsaturated aqueous solutions of some monosaccharides, D-(+)-Glucose, D-(-)-Fructose, D-(+)-Sucrose, has been measured at temperature range from 278.2 - $298.2 \mathrm{~K}$. using an isothermal method. Also, this paper has presented the discussion of the influence of the temperature and sugar concentration with respect to these systems. Also, the knowledge of butyl acetate solubility, in fruits and drinks media at low temperatures will allow a better understanding of the physicochemical interactions of volatile molecules in food and drinks at this range of temperatures. 


\section{MATERIALS AND METHODS}

\section{EXPERIMENTAL}

\subsection{Chemicals}

The sugar compounds (D-Glucose (>99.8\%), D-fructose (>99.0\%) and D-sucrose $(>99.9 \%)$ ) used in the study were all supplied by VETEC Quimica (Rio de Janeiro - Brazil). Butyl Acetate (>99.8\%) was purchased from Reagen. Distilled and deionized water was produced using a academic compact water purification system (Quimis- Brazil). All materials were used as received without any further purification.

\subsection{Apparatus and procedure}

The solubility measurements were performed using an isothermal technique based on the research group experience on solid-liquid and liquid-liquid equilibria [Oliveira et al., 2007-2008; Malagoni and Franco, 2007; Pires and Franco, 2008; Oliveira, 2009].

Jacketed glass cells of about $40 \mathrm{~cm}^{3}$ each were loaded with the appropriate amount of compounds, sugar and water, to perform the desired concentration 10.0-30.0 gL ${ }^{-1}$. Each solution of different composition was prepared by weighting the desired amount of each compound in a \pm 0.0001 g precision balance. Butyl acetate was added to the solution rapidly in a slight excess of over the expected solubility, to a specified liquid sugar solution. Preliminary experiments were made to estimate the amounts to be added of this component. The internal temperature of the cell was controlled by circulating thermostatic liquid in the jacket with a low-temperature thermostat bath (Nova Ética - Brazil) and was also measured with a calibrated thermometer. The thermostatic liquid was a mixture of water and glycerol. The temperature can be considered to be accurate within $\pm 0.1 \mathrm{~K}$. Mixtures were magnetically stirred at constant temperature for at least $2.0 \mathrm{~h}$, the time considered to be sufficient to reach the equilibrium, based on some preliminary tests and according to the experience of the team [Pires and Franco, 2008; Oliveira, 2009]. Once the solution was saturated, the stirring was stopped and the excess aroma gradually supernatant in the surface, resulting in a clear bottom liquid phase. The mixture then was allowed to settle for at least $24 \mathrm{~h}$ at a constant temperature. In intervals of three or more hours, sampling was carefully made in triplicate, using $2 \mathrm{~mL}$ syringes equipped with filter. The solubility of butyl acetate or aroma was determined using a high performance gas chromatography (Focus CG SSl/FID - Thermon Eletron S.p.A) coupled with a FID detector with a OV-5 fused silica capilary columm (30m x $0,25 \mathrm{~mm} \times 0,25 \mu \mathrm{m}, 5 \%$ phenyl-methylpolysiloxane). The temperature of the column was $513.15 \mathrm{~K}$ and the flow rates of gases were: $\mathrm{N}_{2} 30.0 \mathrm{~L} \cdot \mathrm{min}^{-1}$, Synthetic air $280 \mathrm{~L} \cdot \mathrm{min}^{-1}$ and $\mathrm{H}_{2}$ $30.0 \mathrm{~L} \cdot \mathrm{min}^{-1}$. All samples were withdrawn in triplicates. The average standard deviation on the measurements was approximately 0.002 g. $\mathrm{L}^{-1}$.

\section{RESULTS}

It is well know that sugars have very high affinity for water, and considering few concentrations used in trials, so all sugars aqueous solutions had completely dissolution. Relatively few data are available in the literature for sugar mixtures and flavour compounds. 
Some experiments were carried out by monitoring the liquid phase. It was done withdrawing an aliquot of the glucose solution in different intervals of time. Figure 1 is an example of the obtained result. It can be seen that after 22 hours the ester concentration is constant and then, the phases reached equilibrium.

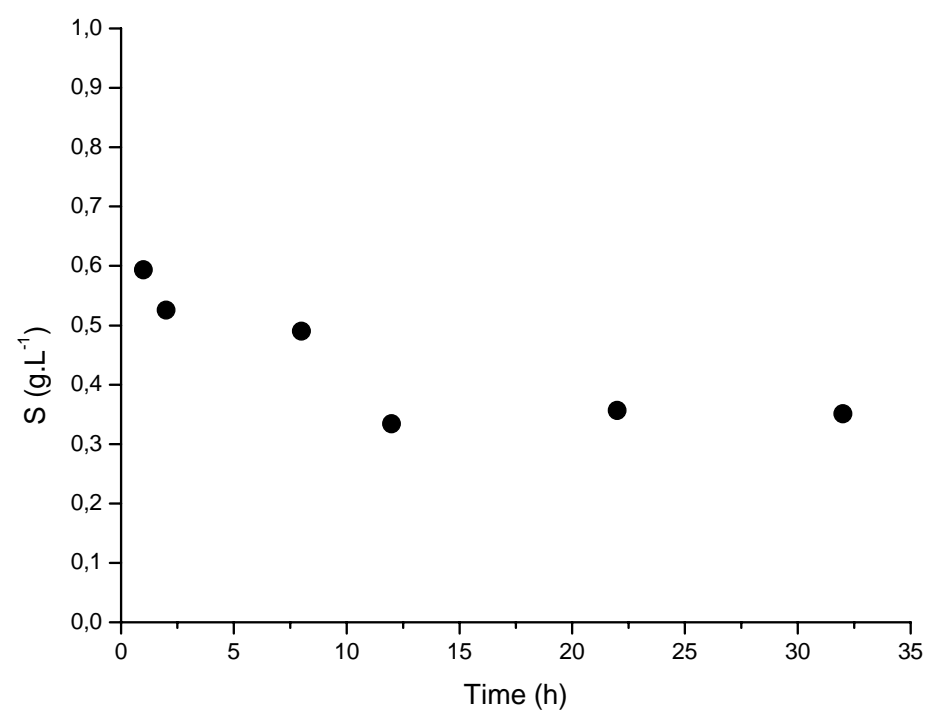

Fig.1. Solubility as a function of time (h) for butyl acetate in glucose solution. (10 $\left.\mathrm{g} \mathrm{L}^{-1}\right)$

The isothermal method was used to determine solubility of butyl acetate in pure water. The results obtained by the application of this method to the acetate are presented in Table 1, where the solubilities are expressed in terms of grams of ester per 100 grams of solution. The solubility of the flavour compound in water presented in Table 1 are compared with the literature and showed good agreement for $298.2 \mathrm{~K}$.

TABLE 1

Solubility of butyl acetate $\left(\mathrm{g} \cdot 100 \mathrm{~g}^{-1}\right)$ in pure water at different temperatures

\begin{tabular}{lccccc}
\hline \multirow{2}{*}{ Reference } & \multicolumn{7}{c}{$\mathrm{T}(\mathrm{K})$} \\
\cline { 2 - 6 } & 278.2 & 283.2 & 288.2 & 293.2 & 298.2 \\
\hline This work & 1.08514 & 0.7748 & 0.7327 & 0.6630 & 0.5917 \\
\hline Literature $1^{*}$ & - & - & - & - & 0.5928 \\
\hline Literature 2* & - & - & - & - & 0.6573 \\
\hline
\end{tabular}

* Smith and Bonner (1950)

** Krupatkin and Glagoleva (1970)

In Table 2, experimental results for solubility of butyl acetate in water/sugar systems at 288.2 K shows the influence of sugar concentration on ester solubility. For solution of water/glucose and water/fructose, solubility of butyl acetate decreased while sugar concentration increased. Furthermore, this behavior was not observed in water/sucrose. 
TABLE 2

Solubility of butyl acetate in water/sugar systems at $288.2 \mathrm{~K}$

\begin{tabular}{lllll}
\hline \multirow{3}{*}{ Ester/sugar } & \multicolumn{2}{l}{ Sugar concentration $\left(\mathrm{gL}^{-1}\right)$} & 20.0 & 30.0 \\
\cline { 2 - 5 } & \multicolumn{3}{l}{10.0} & \\
\cline { 2 - 5 } & Ester solubility $\left(\mathrm{gL}^{-1}\right)$ & & 0.3812 & 0.3107 \\
\hline Butyl acetate/sucrose & 0.2984 & 0.4165 & 0.4132 \\
\hline Butyl acetate/glucose & 0.4608 & 0.5590 & 0.2718 \\
\hline Butyl acetate/fructose & 0.8244 & \\
\hline
\end{tabular}

Figures 2-4 show curves that gives the evolution of the magnitudes, $S\left(\mathrm{~g} .100 \mathrm{~g}^{-1}\right.$, solubility), as a function of temperature for each sugar used. These Figures shows the experimental results and is possible to observe the influence of sugar concentration on butyl acetate solubility. The low retention of butyl acetate in sugars solution, compared with pure water, is really linked to molecular weight of sugars samples involving interactions with macromolecules.

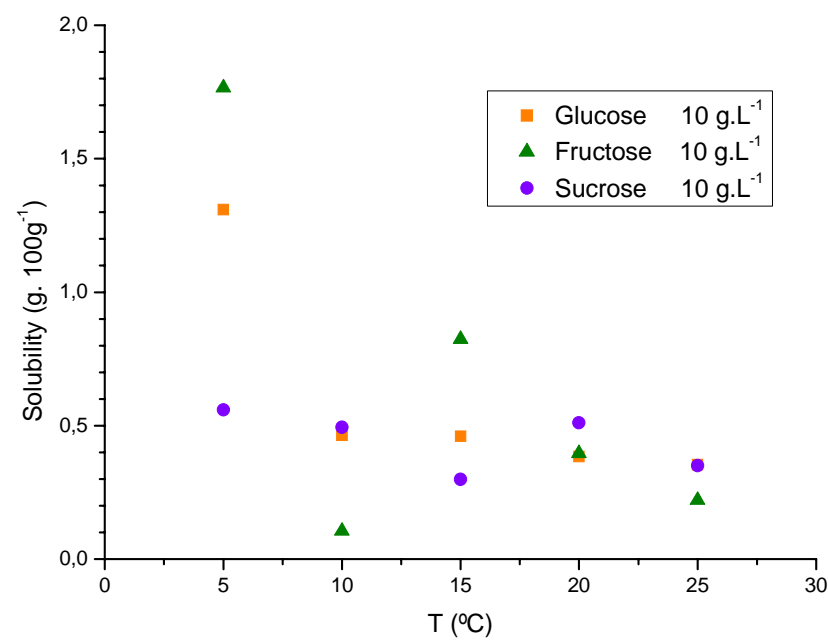

Fig. 2. Solubility of butyl acetate as a function of temperature in aqueous solutions $\left(10 \mathrm{~g} \mathrm{~L}^{-1}\right)$

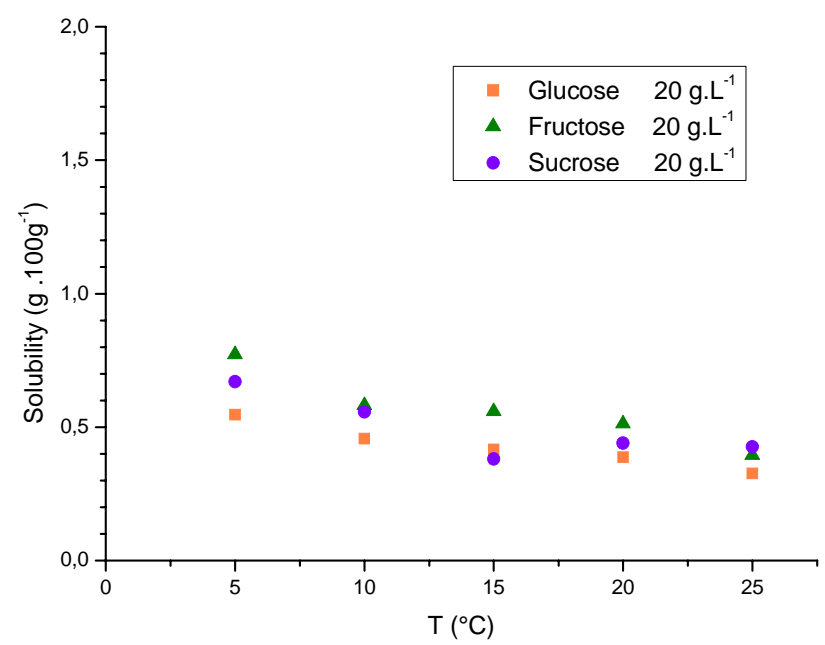

Fig. 3. Solubility of butyl acetate as a function of temperature in aqueous solutions $\left(20 \mathrm{~g} \mathrm{~L}^{-1}\right)$ 
According to the Fig. 3, in mixtures at $20 \mathrm{gL}^{-1}$, solubility of flavour compound at fructose solution was major than glucose and sucrose, in the temperature range studied. In mixtures containing different sugars at concentration equal to $30 \mathrm{~g} \mathrm{~L}^{-1}$ (Fig. 4), the flavour compound was retained more extensively in the presence of glucose agent, compared to in presence of sucrose and fructose.

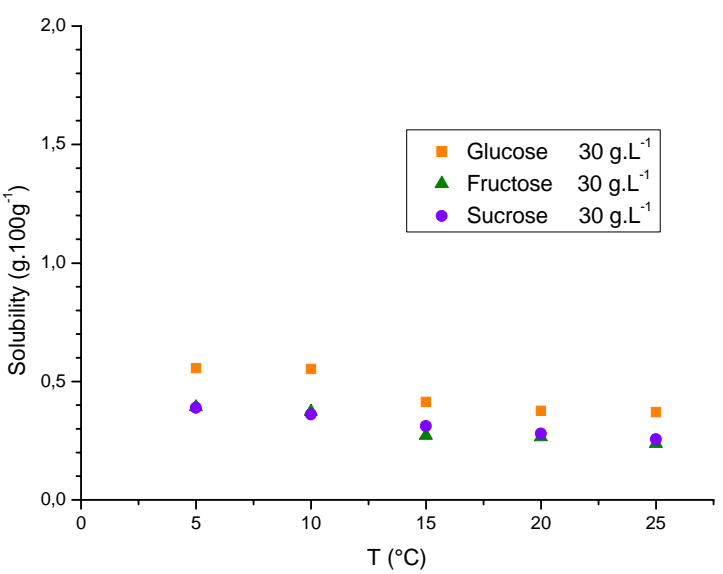

Fig. 4. Solubility of butyl acetate as a function of temperature in aqueous solutions (30 $\left.\mathrm{g} \mathrm{L}^{-1}\right)$

As described in the literature, the molecular weight of polysaccharides is another parameter that can influence the compounds solubility (Goubet, Le Quere \&Volley, 1998). Comparing the results, Fig. 2-4, it is possible to observe the effect of substrate's nature and the concentration on butyl acetate solubility, when substrate concentration increased, solubility decreased and when the molecular weight of substrate is major, as sucrose, the solubility decreased. This both effect were detected by Covarrubias-Cervantes et al. (2005) and they related that this last effect was more important in polyols than in carbohydrates solutions.

The result of increasing the temperature appears to be quite spectacular for butyl acetate, as is illustrated in Fig. 2. For the water/butyl acetate system in the presence of sucrose the rise in temperature produces an insignificant increase in the solubility. In the presence of glucose and fructose, however, there is an important increase in solubility. Thus, it seems that the rise in temperature influences the solubility more than the sugar concentration. Likewise, one may note that the rise in temperature diminishes the solubility of this ester in pure water.

Figure 5 illustrates the influence of the sugar concentration in water-glucose mixtures. Differences between solubility values in any glucose solution were observed for butyl acetate. The effect of temperature for compound followed the same behavior in any aqueous solution as that observed for glucose solutions. Solubility decreased in the range from 298.2 down to $278.2 \mathrm{~K}$. 


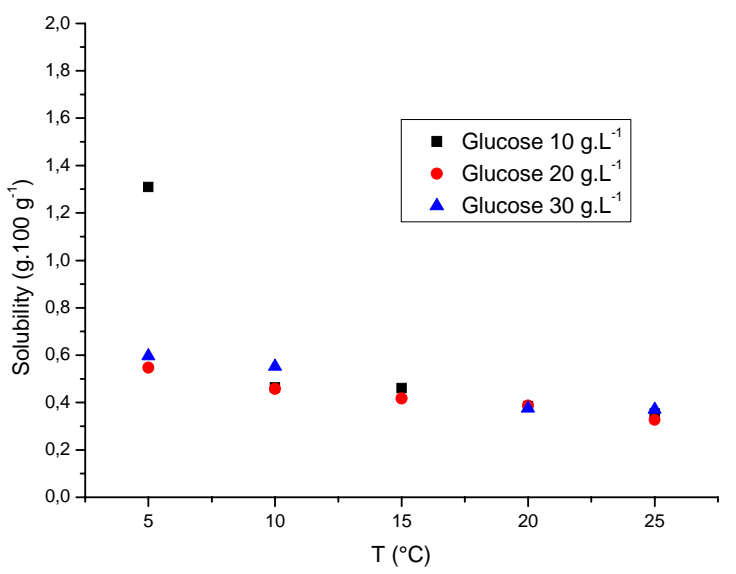

Figure. 5. Solubility of butyl acetate as a function of temperature in mixtures with different glucose concentration $\left(10,20\right.$ and $\left.30 \mathrm{~g} . \mathrm{L}^{-1}\right)$.

According to our finds, it is clear that all sugars studied had a negative influence on butyl acetate solubility compared to in pure water. This result could be explained by the existence of interactions between intermolecular forces and molecules polarity of water, sugar and butyl acetate. Also, the data present in this paper indicate that the temperature significantly affect aroma compounds, and overall quality, during the process and the storage of beverages.

\section{CONCLUSIONS}

The various results presented here emphasize the relations between the molecular structure of sugars and their influence in the butyl acetate solubility in sugar solutions. The establishment of a hydrogen bond with oxygen of a carbonyl group seems to be the essential solubilization factor for the organic molecule. Concerning the effects of sugars, a specific interaction of the molecule with ester has been examined.

Further consideration should be given concerning the influences of the molecular structure of the sugar on ester solubility in the aqueous phase. Judging from the results obtained, it seems that in the higher sugar concentrations the interactions are very similar that the type of sugar has no influence in the measured solubility. Also, increasing the temperature disfavors ester solubility in the aqueous phase.

\section{ACKNOWLEDGEMENTS}

The authors would like to thank FAPEMIG - Fundação de Amparo à Pesquisa no Estado de Minas Gerais, for the financial support.

\section{REFERENCES}

ABDERAFI, S.; BOUNAHMIDI, T. Measurement and estimation of vapor-liquid equilibrium for industrial sugar juice using the Peng-Robinson equation of state Fluid Phase Eq. v. 162 p. 225-240, 1999. 
BLANCH, G. P.; DEL CASTILLO, M. L. R. Changes in strawberry constituents after preharvest treatment with natural hormonal compounds. Flavour Frag. J. v.27, p. 180-187, 2012.

BORGES, R. P.; SILVA, F. C.; FRANCO JR, M. R. Solubility of ethyl acetate in diluted aqueous solutions of fructose. Flavour Frag. J. v.28, p. 10-13, 2013.

COVARRUBIAS-CERVANTES, M.; BONGARD, S.; CHAMPION, D.; VOILLEY, A. Effects of the nature and concentration of substrates in aqueous solutions on the solubility aroma compounds. Flavour Fragr. J. v. 20, p. 265-273, 2004.

COVARRUBIAS-CERVANTES, M.; BONGARD, S.; CHAMPION, D.; VOILLEY, A.. LWT v. 38, p. 371-378, 2005.

FAN, W.; QIAN, M. C. Identification of aroma in Chinese "Yanghe Daqu” liquor by normal phase chromatography fractionation followed by gas chromatography/osfactometry. Flavour Frag. J. v.21, p. 333-342, 2006.

FRANCO, M. R. B.; JANZARANTTI, N. S. Aroma of minor tropical fruits. Flavour Fragr. J. v. 20, p. 358-371, 2005.

GOUBET, I. Le Quere, J.-L, \& Voilley. Retention of aroma compunds by carbohydrates: Influence of their physicochemical characteristics and of their physical state. A review. Journal of Agricultural and Food Chemistry, v. 46(5), p. 1981-1990, 1998.

MALAGONI, R. A.; FRANCO, M. R., Jr. A Simple Apparatus for Data Solubility Determination. Fluid Phase Equilib. v. 255, p. 93-97, 2007.

OLIVEIRA, A. C.; PIRES, R. F.; COELHO, M. G.; FRANCO, M. R., Jr. Solubility of Benzoic Acid in Mixed Solvents. J. Chem. Eng. Data v. 52, p. 298-300, 2007.

OLIVEIRA, M. L. N. Estudo experimental da solubilidade de alguns ácidos em misturas hidro-alcoólicas. (in Portuguese). Doctoral thesis, Faculty of Chemical Engineering, Universidade Federal de Uberlândia, Uberlândia, 2009, 322 p.

OLIVEIRA, M. L. N.; MALAGONI, R. A.; FEHR, M.; FRANCO, M. R., JR. Obtaining Solubility Data from a Liquid-Liquid Equilibrium Cell. Chem. Eng. Commun. v.195, p.10761084, 2008.

PIRES, R. F.; FRANCO, M. R., Jr. Solubility of Benzoic Acid in Aqueous Solutions Containing Ethanol or N-Propanol. J. Chem. Eng. Data v. 53, p. 2704-2706, 2008.

SUOMALAINEN, H.; NYKANEN, L. Aroma of Beer, Wine and Distilled Alcoholic Beverages. Springer London. 424 pgs, 1983. 